\title{
Importance of sigma factor mutations in increased triclosan resistance in Salmonella Typhimurium
}

\author{
Mette Rørbæk Gantzhorn, John Elmerdahl Olsen and Line Elnif Thomsen*
}

\begin{abstract}
Background: Salmonella enterica is the second most common foodborne pathogen. The use of biocides is crucial to prevent spread of foodborne pathogens, and it would be devastating for food safety if Salmonella would become resistant to the disinfectants used. Another concern is that exposure to disinfectants might lead to decreased susceptibility to antibiotics.

The current study aimed to identify genetic changes causing high level triclosan resistance in S. enterica serovar Typhimurium and evaluate how these affected antibiotic resistance and efflux pump activity.

Results: Wild type strains S. Typhimurium 4/74 and DTU3 were adapted to increasing concentrations of the biocide triclosan by serial passage. High level triclosan resistant isolates (MIC > $1000 \mu \mathrm{g} / \mathrm{ml}$ ) were obtained. Strains were genome sequenced, and SNPs in fabl, rpoS and rpoD were found to be associated with high level resistance. However, work with defined mutants revealed that a SNP in fabl was not sufficient to obtain high level resistance. This required additional mutations in the sigma factors rpoS or rpoD. The adapted strains showed triclosan-dependent increased efflux, increased fabl expression and reduced susceptibility towards the antibiotics enrofloxacin and sulphamethoxazole/trimethoprim.

Conclusions: Medium level triclosan resistance could be obtained by fabl mutations in S. Typhimurium, however, high level resistance was found to require sigma factor mutations in addition to a fabl mutation. Reduced antibiotic sensitivity was observed for the adapted strains, which could be associated with increased efflux.
\end{abstract}

Keywords: Triclosan-resistance, Biocides, Antibiotic resistance, fabl, Efflux, Sigma-factors

\section{Background}

Salmonella continues to be an important foodborne pathogen with 91.000 confirmed human cases reported in Europe in 2012 [1]. Among the serovars involved, Salmonella enterica serovar Typhimurium (S. Typhimurium) was the second most important serovar representing $22 \%$ of all confirmed cases [1]. Levels of resistance towards clinically important antibiotics, such as ciprofloxacin, are high in isolates of this serovar from animals and food [2].

Biocides are broadly used to prevent microbial growth and play an important role in preventing the spread of pathogenic bacteria. In recent years there has been

\footnotetext{
* Correspondence: leth@sund.ku.dk
Department of Veterinary Disease Biology, University of Copenhagen, Faculty

*Correspondence: leth@sund.ku.dk
Department of Veterinary Disease Biology, University of Copenhagen, Faculty of Health and Medical Sciences, Stigboejlen 4, 1870 Frederiksberg C, Denmark
}

increasing concern that use of biocides can select for antibiotic cross resistance [3], in addition to causing increased tolerance towards the biocides themselves. During the last 30 years several cases of bacteria developing resistance or tolerance towards biocides, and in some cases cross-resistance to antibiotics, have been reported [4]. Recently, it has been shown that "in-use" concentrations of disinfectants can select multidrug resistant mutants of $S$. Typhimurium [5].

Biocides are used in a wide variety of applications, spanning from preservatives in household-products like vacuum cleaners to disinfectants, make-up and industrial cleaning agents [6]. Especially triclosan, a chlorophenol, has been used in many products, including toothpaste, soaps and as antibacterial agent in toys, fabrics and cutting boards. The effect of triclosan has been extensively

\section{( Biomed Central}


studied. It has been shown that triclosan inhibits the enoyl-acyl carrier protein reductase (FabI) which is involved in fatty-acid biosynthesis in Escherichia coli [7]. In addition, low concentrations of triclosan interfere with nutrient-uptake, whereas high concentrations facilitates membrane leakage by incorporation into the bacterial membrane [8].

Efflux pumps play a role in exporting toxic compounds from the cell and could be a common mechanism for antibiotic and biocide resistance [9]. The efflux systems EmrAB/AcrEF have been found to play a role in the susceptibility of Salmonella towards triclosan [10]. Furthermore, inactivation of the efflux pump genes $a c r B$ and tolC in Salmonella has previously been shown to decrease triclosan resistance [11]. However, proteomic studies of various triclosan-resistant strains revealed that there was no significant overexpression of the AcrABTolC efflux-pump [12], indicating that efflux is not the main mechanism of triclosan resistance [13].

Different genes have been associated with reduced susceptibility to triclosan. Results from E. coli and $S$. aureus have implied that point mutations in $f a b I$ are the primary reason for decreased triclosan sensitivity and that fabI overexpression in E. coli is associated with triclosan resistance [14, 15]. In accordance with this, up-regulation of fabI in Salmonella has been described in response to triclosan exposure, but point mutations or overexpression of $f a b I$ is not sufficient to give high-level resistance in this bacterium, indicating that there are other, yet to be determined, factors involved $[11,16]$. The aim of this study was to determine which mutations, in addition to mutation in $f a b I$, are required for $S$. Typhimurium to obtain high level biocide resistance. To study this, we adapted two different isolates of $S$. Typhimurium to high level triclosan resistance and identified the genes involved in this resistance. In addition, we investigated the effect of the mutations on efflux activity, antibiotic cross resistance and cell culture invasiveness and growth.

\section{Methods}

\section{Bacterial strains}

Bacteria used in this study are listed in Table 1. To evaluate the effect of single SNPs (compared to wild type) from strains adapted to high level triclosan, a single SNP was isolated from other SNPs by transfer to a clean parent strain background by phage transduction using P22 phages. P22 transductions were performed with P22HT105/int ${ }^{-} 201$ as described [17]. A selective pressure of $2 \mu \mathrm{g} / \mathrm{ml}$ of triclosan was used to select for the transfer of the fabI SNP. An rpoS deletion-mutant was constructed by Lambda-Red mediated allelic exchange of the rpoS gene with the chloramphenicol cassette as previously described [18] using the primers rpoSfwd: 5'CAGAATACGCTGAAAGTTCATGATTTA
AATGAAGACGCgtgtaggctggagctgcttc3' and rpoSrev: 5'GCGGAA CAGCGCTTCGATATTCAGCCCCTGCG TCTGCAcatatgaatatcctccttag3' in 4/74. The mutant was verified using a PCR-strategy with the primers rpoScon: 5'-GGATCACGGGTAGGAGCCACCTTTTG AG and camfwdny: 5'-TACGCAAGGCGACAAGGTG CTGATGCCG as previously described [19]. The deletion of rpoS was transferred to TDTU3C by P22 phage mediated general transduction. Mutations were confirmed by PCR and sequencing. Strains were maintained in LB-Lennox broth (LB) (BD Difco ${ }^{\mathrm{Tm}}$ ). For growth on solid media, LB was added $1.5 \%$ agar producing LB agar plates.

\section{Biocide solutions}

A stock solution of $50 \mathrm{~g} / \mathrm{L}$ triclosan (Irgasan, SigmaAldrich, Broendby Denmark) was made in $70 \%$ ethanol and from here a solution of $300 \mu \mathrm{g} / \mathrm{ml}$ was prepared in sterile MilliQ-water and kept at $5{ }^{\circ} \mathrm{C}$ until precipitations had dissolved, usually $18-20 \mathrm{~h}$.

\section{Adaptation to high concentrations of biocides}

Adaptation to high concentrations of biocides was obtained by daily sub-cultivations using an oblique-plate assay modified from assays previously described $[20,21]$. Briefly, 3x700 $\mu$ l MHB (Müller Hinton broth, Oxoid A/S, Roskilde, Denmark) was inoculated with one colony and incubated at $37^{\circ} \mathrm{C}$ with shaking for $3.5 \mathrm{~h}$. Plates containing a maximum concentration of $1 / 2$ MIC were streak-

\begin{tabular}{|c|c|c|}
\hline Strain & Properties & Origin/reference \\
\hline $4 / 74$ & Wild type & 30 \\
\hline $\mathrm{K} 4 / 74$ & $\begin{array}{l}\text { Control, } 4 / 74 \text { sub-cultured without } \\
\text { triclosan as many times as adapted } \\
\text { strains }\end{array}$ & This study \\
\hline $\mathrm{T} 4 / 74 \mathrm{~A}$ & 4/74 adapted to triclosan & This study \\
\hline $\mathrm{T} 4 / 74 \mathrm{~B}$ & 4/74 adapted to triclosan & This study \\
\hline $\mathrm{T} 4 / 74 \mathrm{C}$ & 4/74 adapted to triclosan & This study \\
\hline 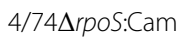 & rpos deletion mutant & This study \\
\hline $\mathrm{T} 4 / 74-f a b l$ & fabl G93S & This study \\
\hline DTU3 & Wild type (DFVF/FOOD: 2009-60-277) & This study \\
\hline KDTU3 & $\begin{array}{l}\text { Control, DTU3 sub-cultured without } \\
\text { triclosan as many times as adapted } \\
\text { strains }\end{array}$ & This study \\
\hline TDTU3A & DTU3 adapted to triclosan & This study \\
\hline TDTU3B & DTU3 adapted to triclosan & This study \\
\hline TDTU3C & DTU3 adapted to triclosan & This study \\
\hline DTU3-fabl & fabl G93S & This study \\
\hline DTU3-fabl-rpos & $\begin{array}{l}\text { rpos }(\mathrm{R} 100 \mathrm{H}) \text { from TDTU3C } \\
\text { transduced into DTU3-fabl }\end{array}$ & This study \\
\hline $\begin{array}{l}\text { TDTU3CArpos: } \\
\text { Cam }\end{array}$ & rpos deletion mutant & This study \\
\hline
\end{tabular}


inoculated starting from the highest concentration in triplicate. After incubation overnight at $37{ }^{\circ} \mathrm{C}$ colony material swabbed from growth at the highest concentration were suspended in $1 \mathrm{ml}$ sterile $0.9 \% \mathrm{NaCl}$ and sub-cultivated daily on the same concentration until growth occurred in the full length of the plate on two subsequent days, then the concentration was doubled. Adaptation was ended after five subsequent days using same concentration with no increase in the extent of growth. Control-adaptations were done on plates not containing biocide to examine the effect of subcultivations alone. Adaptation stability was examined by growth in media without biocide for five subsequent days with daily passage.

\section{MIC-determinations}

MIC determinations for biocides were done by micro dilution assay as previously described [22]. Strains adapted to biocides were tested in concentrations ranging from $8-4000 \mu \mathrm{g} / \mathrm{ml}$ and non-adapted strains (wild type and control-adapted strains) were tested in concentrations $0.14-64 \mu \mathrm{g} / \mathrm{ml}$. All MIC determinations were done in technical duplicate and biological triplicate.

\section{Antibiotic susceptibility tests}

Susceptibility towards antibiotics was examined in biological triplicate using disk diffusion according to EUCAST guidelines version 3.0, 24 April, 2013 using Müller Hinton agar (MHA) (Oxoid A/S, Roskilde, Denmark). Furthermore antibiotic resistance tests were performed on MHA containing triclosan in concentrations of 1 and $1000 \mu \mathrm{g} / \mathrm{ml}$. Statistical analysis was performed on zone diameters varying $>2 \mathrm{~mm}$ compared to wild type.

\section{MBC determinations}

Minimum bactericidal concentrations (MBCs) towards biocide were estimated by spot plating $2 \times 10 \mu \mathrm{l}$ on LB agar from inoculum and all wells without growth from the MIC-plate after incubation. MBC was determined as the lowest concentration giving more than a 5-log reduction of inoculum.

\section{Genome sequencing and SNP detection}

Both parent strains and all adapted strains including controls were sequenced. DNA was extracted from overnight cultures using DNeasy Blood and Tissue Kit (Qiagen) according to manufactures instructions. Genome sequencing was done at the National High-Throughput Sequencing Centre, University of Copenhagen, Denmark using Illumina HiSeq 2000 paired end reads with a coverage of 100-200 bp. Sequences were analyzed for the presence of SNPs and other genomic variations using CLC Genomic Workbench 5.5.1 probalistic variant detection after mapping to the annotated genome of $S$. Typhimurium strain 4/74 (CP002487) [23]. Variants of DTU3 were filtered against control-reads of DTU3wt with a control read count threshold of 20 prior to analysis. Mapping of $4 / 74$ revealed $100 \%$ coverage and the mapping of DTU3 showed 98\% coverage meaning that the sequenced obtained from DTU3 covered 98\% of the published genome of $4 / 74$, which primarily contained genes encoding phage proteins, prophages and other phage related structures.

\section{Growth curves}

Growth was evaluated with and without triclosan in a concentration of $0.3 \mu \mathrm{g} / \mathrm{ml}$. Growth curves were obtained using Bioscreen C (Finland) in a final volume of $200 \mu \mathrm{l}$ Müller Hinton broth (MHB). The inoculum was $5 \mu$ l overnight $(\mathrm{ON})$ culture diluted to an $\mathrm{OD}_{600}=0.05$, giving a final OD in the wells of 0,001 (about $1^{*} 10^{6} \mathrm{CFU} / \mathrm{ml}$ ). Plates were incubated at $37{ }^{\circ} \mathrm{C}$ in Bioscreen $\mathrm{C}$ with medium shaking for $10 \mathrm{sec}$ before each measurement. $\mathrm{OD}_{600}$ was measured every $20 \mathrm{~min}$ for $23 \mathrm{~h}$. Growth curves were performed in biological triplicate.

\section{Efflux pump activity}

Efflux pump activity was evaluated using the Cartwheel method modified from [24]. The inoculum was prepared by growing the strains for $4 \mathrm{~h}$ in $\mathrm{LB}$ at $37^{\circ} \mathrm{C}$ with shaking. Efflux was evaluated in increasing concentrations of triclosan $(0.25-1000 \mu \mathrm{g} / \mathrm{ml})$ with fixed concentration of ethidium bromide of $1 \mu \mathrm{g} / \mathrm{ml}$. Fluorescence was examined using GelDoc (Bio-Rad Laboratories, Inc.).

\section{Northern blot}

Northern blot analysis was performed as previously described [25]. Cells at mid-exponential phase $\left(\mathrm{OD}_{600}=0.5\right.$ $+/-0.05)$ and stationary phase $\left(\mathrm{OD}_{600}=1.2+/-0.1\right)$ grown with and with-out triclosan at a concentration of $0.3 \mu \mathrm{g} / \mathrm{ml}$ were harvested by centrifugation for $8 \mathrm{~min}$ at $10.000 \mathrm{rpm}$. The pellet was stored at $-80{ }^{\circ} \mathrm{C}$. Probes targeting fabI transcript was amplified by PCR using fabIf: 5'AAGCGCATTCTGGTCACTGG3' and fabIr: 5'TTCAATGGTCACGGTGCGAC3' and labeled with $\left[\alpha-{ }^{32} \mathrm{P}\right] \mathrm{dCTP}$.

\section{Cell culture infections}

Cell-assays were performed using INT-407 (HeLa contaminated epithelial cell-line) as previously described [26] with few modifications: Cells were seeded at $5 \times 10^{5}$ cells/ well in 24-well plates and grown overnight at $37^{\circ} \mathrm{C}$ supplemented with $5 \% \mathrm{CO}_{2}$ in MEM $(1 \mathrm{X})+$ GlutaMAX $^{\mathrm{m}}-\mathrm{I}$ (Gibco ${ }^{\circ}$ by life technologies ${ }^{\mathrm{mn}}$ ) supplemented with $10 \%$ heat treated Fetal Bovine Serum (FBS) (Gibco ${ }^{\circ}$ by life technologies ${ }^{\mathrm{mm}}$ ). Bacteria from overnight LB cultures were diluted to $\mathrm{OD}_{600}=0.05$ and grown for two hours before 
harvesting and adjusting $\mathrm{OD}_{600}$ to 0.1 . Cells were infected in technical duplicate with a MOI of 50:1 for $30 \mathrm{~min}$ before wash with warm $0.9 \% \mathrm{NaCl}$. For determination of invasion wells were added $0.5 \mathrm{ml}$ fresh $\mathrm{MEM}+10 \% \mathrm{FBS}$ with $100 \mathrm{\gamma}$ Gentamycin and incubated for $2 \mathrm{~h}$ at $37^{\circ} \mathrm{C}$ supplemented with $5 \% \mathrm{CO}_{2}$. At both time-points $(30 \mathrm{~min}$ and $30 \mathrm{~min}+2 \mathrm{~h}$ ) cells were washed and lysed using $0.1 \%$ TritonX-100 before serial dilution and plating at LB agar for CFU counts. Lysates and inoculum was plated on LB agar in technical duplicate to establish CFU/ml and hence calculate adhesion-and invasion-efficiency. Cell-assays were done in biological duplicate.

\section{Statistics}

For the analysis of differences in antibiotic resistance a mixed linear model was used. Each concentration of triclosan was analyzed separately, and zone diameters of the adapted strains at triclosan concentration of $1000 \mu \mathrm{g} /$ $\mathrm{ml}$ were compared to wild type strains at triclosan concentration of $1 \mu \mathrm{g} / \mathrm{ml}$. Zone diameter for each antibiotic were the response variable and strain were the explanatory variable. Date of antibiotic testing was included as a random factor. The statistical analysis was performed using the program $R$ [27] and the packages "lme4" [28] and "multcomp" [29]. Student's t-test in Excel 2010 (Microsoft) was used to analyse differences in adhesion and invasion between strains. Significance levels were set at $5 \%$.

\section{Results}

Salmonella Typhimurium isolates with tolerance to high concentration of triclosan are easily obtained after exposure to triclosan

Two different $S$. Typhimurium strains, the clinical isolate 4/74 [30] and the pork slaughterhouse isolate DTU3 were exposed to triclosan to evaluate the ability to obtain resistant mutants and to elucidate the genetics behind this adaptation. Adaptation was done using daily sub-culturing on gradient plates containing increasing concentrations of triclosan. Three biologically independent adapted strains were isolated for each wild type strain. Before adaptation, the triclosan MIC values for $4 / 74$ and DTU3 were $1 \mu \mathrm{g} / \mathrm{ml}$ and $8 \mu \mathrm{g} / \mathrm{ml}$, respectively. After 36 sub-cultivations the MIC had increased to 1057-2088 $\mu \mathrm{g} /$ $\mathrm{ml}$ for strain 4/74, subcultures A-C (from here on designated $\mathrm{T} 4 / 74$ strain $\mathrm{A}-\mathrm{C}$ ) and $2088-4124 \mu \mathrm{g} / \mathrm{ml}$ for TDTU3 strains A-C (Table 2). MBC-values, defined as the lowest concentration giving a 5-log reduction of inoculum, were shown to be $4124 \mu \mathrm{g} / \mathrm{ml}$ and $4124-8146 \mu \mathrm{g} / \mathrm{ml}$ respectively (Table 2). To evaluate the stability of the phenotype, the adapted strains were subsequently grown five days without triclosan and were found to maintain their high level resistance (data not shown). This indicated that the adaptation was caused by genetically inheritable
Table 2 MIC and MBC values $(\mu \mathrm{g} / \mathrm{ml})$ of triclosan for $\mathrm{S}$ Typhimurium wild type and mutants

\begin{tabular}{lll}
\hline Strain & MIC & MBC \\
\hline 4/74 (wild type) & 1 & $>64$ \\
K4/74 & 0.5 & $\mathrm{ND}$ \\
T4/74A & 2088 & 4124 \\
T4/74B & 1057 & 4124 \\
T4/74C & 2088 & 4124 \\
4/74-fabl & 270 & $\mathrm{ND}$ \\
DTU3 (wild type) & 8 & $>64$ \\
KDTU3 & 8 & $\mathrm{ND}$ \\
TDTU3A & 2088 & 4124 \\
TDTU3B & 2088 & 8146 \\
TDTU3C & 4124 & 8146 \\
DTU3-fabl & 64 & $\mathrm{ND}$ \\
DTU3-fabl-rpoS & 4124 & $\mathrm{ND}$ \\
TDTU3C $\Delta$ rpos::Cam & $\leq 0.14$ & $\mathrm{ND}$ \\
\hline
\end{tabular}

ND: Not determined

mutations rather than development of phenotypic tolerance. The control strains K4/74 and KDTU3 were similarly exposed to 36 sub-cultivations, but without triclosan. Both control strains maintained the wild type MIC (Table 2).

\section{Concurrent mutations in fabl and sigma-factor leads to high-level resistance}

To elucidate the changes responsible for triclosan resistance, genome sequencing of the strains was conducted. The genome sequences of the adapted strains were compared to the corresponding control strains and revealed between two to seven changes (Table 3). Only non-synonymous changes in coding regions were considered. A Gly-93 $\rightarrow$ Ser mutation in $f a b I$ was present in all adapted strains with the exception of TDTU3C for which a Gly-93 $\rightarrow$ Val mutation in $f a b I$ was present. Mutations were also found in several other genes including rpoD and $n d h$ (T4/74C) and rpoS (TDTU3C) (Table 3). We focused our investigations on the two adapted strains, T4/74C and TDTU3C to elucidate the importance of the SNPs in the sigma factors, rpoD and rpos. To investigate whether mutations in the adapted strains had an effect on fitness, their growth was compared to the control strains. We found that the adapted strains T4/74C and TDTU3C and their corresponding control strains showed similar growth (data not shown). To evaluate the importance of the sigma factor SNPs, we constructed a mutant harboring only the $f a b I$ mutation by transferring the fabI SNP of T4/74C to the wild type strain $4 / 74$, obtaining the strain 4/74-fabI. This strain had higher MIC $(270 \mu \mathrm{g} / \mathrm{ml})$ than parent wild type strain, but did not show 
the same high MIC to triclosan as the adapted strain, that also contained the $n d h$ and rpoD mutations (Table 2). Similarly, the MIC of a DTU3-fabI mutant $(64 \mu \mathrm{g} / \mathrm{ml})$, without the SNP in rpoS was also found to be 4 times higher than the wild type, but 64 fold lower than the TDTU3C strain (Table 2). Introducing the rpoS mutation $(\mathrm{R} 100 \mathrm{H})$ into DTU3-fabI by phage transduction reestablished the high triclosan MIC, confirming that both mutations have to present to obtain high level resistance (Table 2). The importance of a mutation in a sigma factor was consistent with the observations in the adapted strain TDTU3C, which only had mutations in the sigma factor rpoS in addition to the mutation in fabI. Furthermore, the significance of a functional sigma factor for high triclosan resistance was shown by deleting the rpoS gene in the TDTU3C strain resulting in the mutant TDTU3C $\Delta r p o S::-$ cam which had lost its high level resistance (Table 2).

Mutations in $f a b I$ was found in all our adapted strains and increased expression of fabI has previously been shown to affect triclosan resistance [11]. To evaluate if the SNPs identified altered the expression of fabI, the amount of fabI mRNA was compared between the adapted strains and the wild type. Examination of $f a b I$ expression using Northern Blot showed a minor up-regulation of fabI in the two adapted strains (data not shown). This corresponds with previously published observations of triclosaninduced fabI expression [11, 31].

\section{Antibiotic resistance and efflux pump activity in triclosan adapted strains}

There is an increasing concern that adaptation to biocides could lead to cross resistance to other antimicrobial compounds, including antibiotics used in the clinical setting [6]. Antibiotic resistance analysis was done using disc-diffusion on plates with and without triclosan. When comparing wild type, control and adapted strains, we observed only slight decreases in zone diameter for the adapted strain T4/74C with enrofloxacin (ENR), and for TDTU3C exposed to sulfamethoxazole/trimethoprim (SXT), indicating reduced sensitivity (Table 4). On the other hand, the adapted strain $\mathrm{T} 4 / 74 \mathrm{C}$ showed a small increase in zone diameter regarding amoxicillin/clavulanic acid (AMC) and TDTU3C regarding ENR. However, when the tests were done using plates with triclosan in concentrations of $1000 \mu \mathrm{g} / \mathrm{ml}$ a highly significant decrease in zone-diameter was seen towards SXT $(\mathrm{p}<0.001)$ and ENR $(\mathrm{p}<0.001)$ for both T4/74C and TDTU3C (Table 4). The opposite was observed regarding cefotaxime (CTX), where both of the adapted strains showed a significant increase in zone diameter, and similarly for 4/74C exposed to ceftiofur (EFT) $(\mathrm{p}<0.001)$.

Triclosan resistance can be caused by efflux pumps which are also known to affect resistance to antibiotics [32]. Since we observed antibiotic cross resistance when high triclosan concentrations were present, we investigated whether increasing triclosan concentrations could lead to increased efflux. We evaluated efflux activity by using accumulation of ethidium bromide (EtBr) as an indicator of the level of efflux. EtBr traverses the bacterial cell wall and once inside it binds to DNA and fluoresces in ultraviolet light. Bacterial efflux pumps recognize $\mathrm{EtBr}$ and are able to extrude it to the medium meaning that low fluorescence is indicative of high efflux. Our experiments revealed a correlation between

Table 3 Non-synonymous mutations within coding regions of adapted strains

\begin{tabular}{|c|c|c|c|c|c|c|}
\hline Protein & $\mathrm{T} 4 / 74 \mathrm{~A}$ & $\mathrm{~T} 4 / 74 \mathrm{~B}$ & $\mathrm{~T} 4 / 74 \mathrm{C}$ & TDTU3A & TDTU3B & TDTU3C \\
\hline STM474_0600 Putative regulatory protein & & Q19* & & & & \\
\hline Ndh NADH dehydrogenase & & G66V & G66V & & & \\
\hline SelD Selenophosphate synthetase & D327V & & & & & \\
\hline STM474_1682 Invasion-like protein & F131fs & & & & & \\
\hline Fabl enoyl-(acyl-carrier protein) reductase & G93S & G93S & G93S & G93S & G93S & G93V \\
\hline RfbV Abequosyl transferase & K177fs & & & & & \\
\hline RcsB Transcriptional regulator & V149fs & & & & & \\
\hline RpoD RNA polymerase sigma factor & & & T119| & & & \\
\hline STM474_2675 Putative phosphotransferase system IIB component & A83V & & & & & \\
\hline Fis DNA binding protein & A78D & & & & & \\
\hline STM474_0304 Putative RHS-like protein & & & & $\mathrm{F} 25 \mathrm{~V}$ & F25V & \\
\hline NadE NAD synthetase & & & & L214S & L214S & \\
\hline RpoS RNA polymerase sigma factor & & & & & & $\mathrm{R} 100 \mathrm{H}$ \\
\hline SspA Stringent starvation protein A & & & & E153* & E153* & \\
\hline TrpS Tryptophanyl-tRNA synthetase & & & & $\mathrm{T} 781$ & T78। & \\
\hline
\end{tabular}

*: stop codon, fs: frame shift-leading to stop codon 
efflux and concentration, showing increased efflux when the adapted strain was exposed to triclosan in high concentrations (Fig. 1). At low concentrations $(0,5$ and $5 \mu \mathrm{g} / \mathrm{ml})$, high level fluorescence was observed as a highly fluorescent streak of bacteria. This corresponds with high level of intracellular $\mathrm{EtBr}$ caused by low efflux. At 500 and $1000 \mu \mathrm{g} / \mathrm{ml}$ triclosan, the bacterial streak only shows low level fluorescence, which indicates high efflux and limited binding of EtBr to the DNA in the cell.

\section{Cell culture adhesion and invasion of triclosan adapted strains}

Previous results have shown a link between triclosan resistance and virulence factor expression in Gram positive bacteria and reduced invasiveness after prolonged treatment of $S$. Typhimurium with disinfectants $[4,20]$. We therefore investigated the ability of the adapted strains to adhere to and invade the cell-line INT407. We found a small, but significantly decreased ability of the adapted strain TDTU3C to adhere and invade compared to the wild type and control strains. However, the inoculum was also slightly decreased for the TDTU3C strain. $4 / 74 \mathrm{C}$ did not show reduced adherence and invasion compared to the control strain K4/74 (Fig. 2). The control strain $K 4 / 74$ revealed a decreased ability to invade compared to the wild type, however it also showed a decreased adhesion, which could account for the lower ability to invade. Our results therefore indicate that the mutations do not have any major effect on virulence for the two strains.

\section{Discussion}

In the present study, we have investigated the genetic background for the ability of $S$. Typhimurium to adapt to triclosan. Adaptation was found to be relatively easy and we were able to adapt two different strains of clinical and slaughterhouse origin to grow in concentrations equal to or above $1000 \mu \mathrm{g} / \mathrm{ml}$.

The mechanisms of resistance towards triclosan have been studied quite intensively, but still the exact mechanisms are not fully understood [11-13, 16, 33-36]. To further elucidate the genetics behind this adaptation, we genome sequenced the adapted strains and compared the sequence to the control strains. In all adapted strains, a mutation was present in fabI, however other mutations were also present. From our genome sequencing results and subsequent construction of mutants containing $f a b I$ from the adapted strains, we can conclude that having a mutation in fabI leads to increased triclosan tolerance, but is not enough to confer high level resistance.

Our results show that mutations in one of the sigma factors $r p o S$ or $r p o D$, in addition to the fabI mutation, caused high resistance levels in T47/4C and TDTU3C. This corresponds with previous results showing that fabI mutations are involved in triclosan resistance, but do not alone account for high level resistance [11]. The authors demonstrated that a variety of other genes, including $\operatorname{arc} B, \operatorname{tol} C$ and $\operatorname{ram} A$ can be involved in triclosan resistance [11]. Although, it has been shown, that triclosan induce rpoS expression in $S$. Typhimurium [16], implying its importance for a triclosan response,

Table 4 Zone diameters of wild type and adapted strains without and with concurrent exposure to triclosan

\begin{tabular}{|c|c|c|c|c|c|c|c|c|c|c|c|c|c|c|c|c|c|c|c|c|c|c|}
\hline & $\begin{array}{l}\text { Triclosan } \\
\text { concentration } \\
(\mu \mathrm{g} / \mathrm{ml})\end{array}$ & TET & SD & SXT & SD & & ENR & SD & & AMC & SD & & GEN & SD & EFT & SD & & AMP & SD & CTX & SD & \\
\hline $4 / 74$ & 0 & 24 & 2,04 & 25 & 1,47 & & 32 & 2,40 & & 24 & 3,39 & & 25 & 3,35 & 26 & 2,35 & & 23 & 4,29 & 32 & 3,58 & \\
\hline $\mathrm{K} 4 / 74$ & 0 & 24 & 1,14 & 26 & 1,58 & & 33 & 1,95 & & 24 & 3,49 & & 24 & 4,03 & 25 & 0,71 & & 23 & 2,68 & 33 & 0,96 & \\
\hline T4/74C & 0 & 23 & 1,47 & 25 & 1,05 & & 30 & 3,29 & & 27 & 2,17 & $*$ & 23 & 2,41 & 26 & 1,63 & & 24 & 2,58 & 34 & 1,67 & \\
\hline $4 / 74$ & 1 & 25 & 1,41 & 26 & 0,00 & & 35 & 1,41 & & 25 & 4,24 & & 29 & 7,07 & 28 & 3,54 & & 25 & 7,78 & 37 & 3,54 & \\
\hline $\mathrm{K} 4 / 74$ & 1 & 25 & 0,71 & 27 & 2,12 & & 34 & 0,71 & & 25 & 2,12 & & 27 & 2,83 & 26 & 0,71 & & 25 & 1,41 & 34 & 0,71 & \\
\hline $\mathrm{T} 4 / 74 \mathrm{C}$ & 1 & 24 & 1,76 & 24 & 1,37 & & 30 & 3,20 & & 26 & 1,83 & & 24 & 2,86 & 25 & 2,48 & & 24 & 2,28 & 33 & 2,83 & \\
\hline $\mathrm{T} 4 / 74 \mathrm{C}$ & 1000 & 24 & 5,18 & 14 & 1,17 & $* * *$ & 11 & 1,75 & $* * *$ & 32 & 6,57 & & 29 & 6,00 & 33 & 1,67 & $* * *$ & 31 & 8,35 nd & 43 & 3,83 & $* * *$ \\
\hline DTU3 & 0 & 6 & 0,00 & 22 & 2,06 & & 29 & 1,15 & & 18 & 4,43 & & 26 & 1,53 & 24 & 1,71 & & 6 & 0,00 & 30 & 1,53 & \\
\hline KDTU3 & 0 & 6 & 0,00 & 21 & 1,22 & & 29 & 1,22 & & 17 & 4,69 & & 25 & 0,96 & 24 & 1,48 & & 6 & 0,00 & 30 & 1,00 & \\
\hline TDTU3C & 0 & 6 & 0,00 & 20 & 1,67 & & 30 & 1,10 & & 17 & 4,34 & & 24 & 3,10 & 24 & 1,52 & & 6 & 0,00 & 31 & 0,82 & \\
\hline DTU3 & 1 & 6 & 0,00 & 22 & 1,41 & & 31 & 0,71 & & 17 & 4,95 & & 27 & 1,41 & 25 & 0,71 & & 6 & 0,00 & 31 & 2,12 & \\
\hline KDTU3 & 1 & 6 & 0,00 & 23 & 0,71 & & 31 & 0,71 & & 15 & 3,54 & & 26 & 0,71 & 25 & 0,71 & & 6 & 0,00 & 31 & 3,54 & \\
\hline TDTU3C & 1 & 6 & 0,00 & 21 & 1,52 & & 29 & 0,89 & & 16 & 4,51 & & 26 & 1,26 & 25 & 1,52 & & 6 & 0,00 & 31 & 1,00 & \\
\hline TDTU3C & 1000 & 6 & 0,00 & 13 & 1,79 & $* * *$ & 11 & 0,84 & $* * *$ & 19 & 5,18 & & 27 & 2,75 & 26 & 1,14 & & 6 & 0,00 & 35 & 3,79 & * \\
\hline
\end{tabular}

TET: Tetracycline, SXT: trimethoprim/sulfamethoxazole, ENR: enrofloxacin,AMC: ampicillin/clavulanic acid, GEN: gentamicin, EFT: ceftiofur, AMP: ampicillin, CTX: Cefotaxime. Susceptibility towards antibiotics was examined in biological triplicate. Asterisk indicate level of significant difference from wild type (4/74 or DTU3): ${ }^{*} \mathrm{p} \leq 0.05,{ }^{* * *} \mathrm{p} \leq 0.001, \mathrm{nd}$ : not determined 


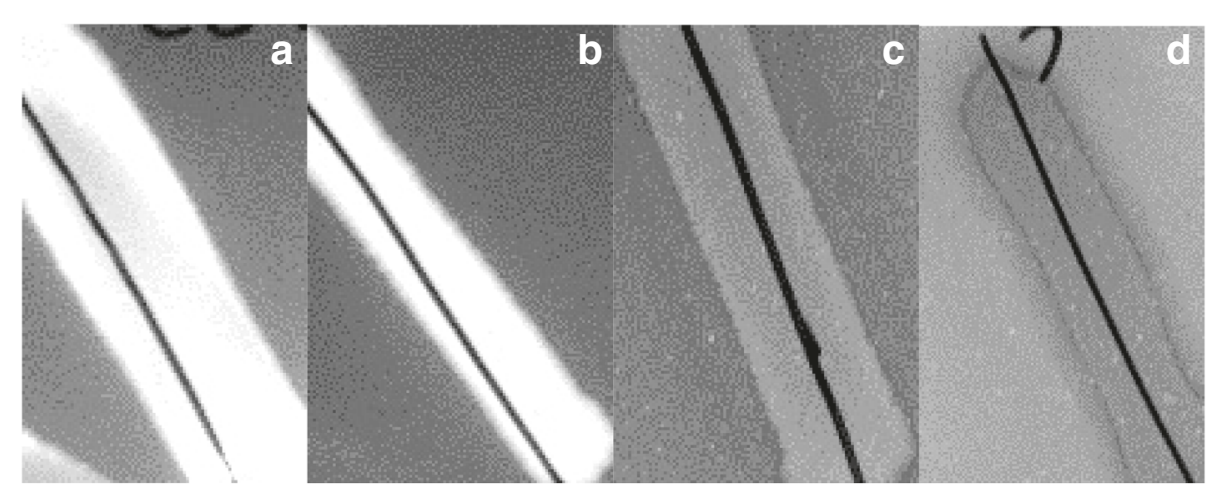

Fig. 1 Fluorescence decreases at high concentrations of triclosan indicating higher efflux. High level of fluorescence of TDTU3C is observed at triclosan concentrations of $0,5 \mu \mathrm{g} / \mathrm{ml}(\mathbf{a})$ and $5 \mu \mathrm{g} / \mathrm{ml}(\mathbf{b})$ indicating low efflux of EtBr. Low fluorescence is seen at triclosan concentrations of $500 \mathrm{\mu g} / \mathrm{ml}(\mathbf{c})$ and $1000 \mu \mathrm{g} / \mathrm{ml}$ (d) indicating high efflux. Concentration of ethidium bromide is $1 \mathrm{\mu g} / \mathrm{ml}$

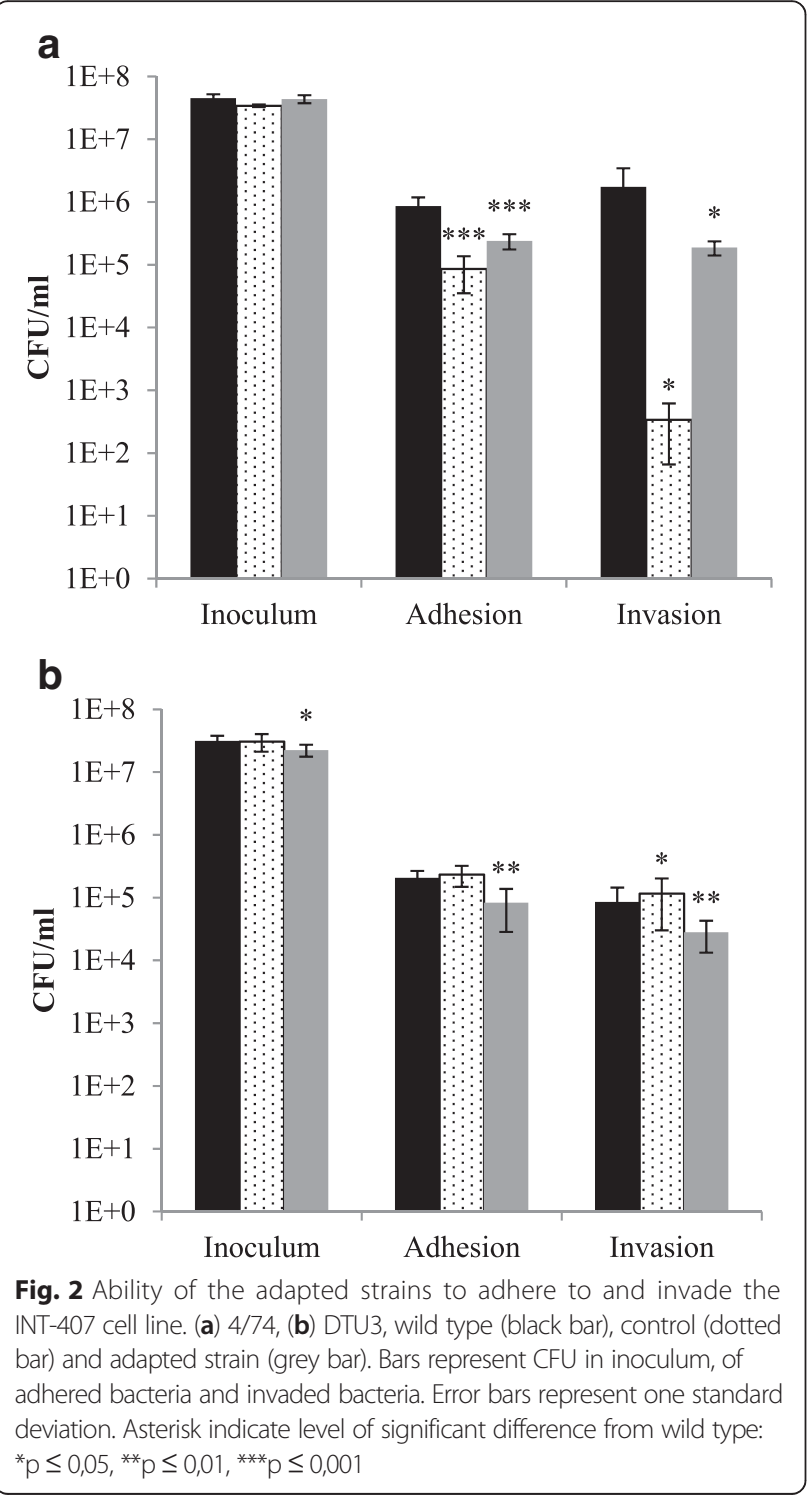

we show, to the best of our knowledge, for the first time that mutations in sigma factors contribute to triclosan resistance. Sigma factors are required for transcription initiation and mutations in rpoS or rpoD indicate that changes in gene expression levels influence high level triclosan resistance. Our data show a triclosan dependent increase in fabI expression and increased efflux pump activity, both of which could be the result of changed expression levels caused by the sigma factor mutations.

In addition to the $f a b I$ and sigma factor mutation, we also found a mutation in $n d h$ in T4/74C. The function of $n d h$ is not fully understood, but it has been proposed that it is involved in rapid NADH recycling [37]. Since triclosan is known to bind NADH, it is not unlikely that this mutation has some additional effect on susceptibility or fitness of the strain. However, since we have found no mutations in $n d h$ or other similar genes in TDTU3C, we did not consider the $n d h$ mutation to be as important as the mutation in the sigma factor. It is, however, important to notice, that high level resistance to triclosan can be achieved with no mutations in sigma factors or $n d h$, as evident from the adapted strains T4/74A, TDTU3A, and TDTU3B. Further studies are needed to elucidate whether such strains harbours mutations in genes that are directly or indirectly regulated by RpoS or RpoD, eliminating the need for mutation in the regulatory gene(s).

Several researchers have been able to adapt Salmonella and other bacteria to certain biocides and the concern is that the mechanisms resulting in biocide resistance may confer cross resistance to antibiotics $[4,38,39]$. In this study, we found a decreased susceptibility of $\mathrm{T} 4 / 74 \mathrm{C}$ and TDTU3C towards enrofloxacin and sulfamethoxazole/trimethoprim, respectively.

A highly interesting observation was that concurrent exposure to high concentrations of triclosan conferred a marked decrease in zone diameters of the adapted strains 
towards enrofloxacin and sulfamethoxazole/trimethoprim. A possible explanation could be the induction of efflux by triclosan. We found that increased efflux of $\mathrm{EtBr}$ was linked to increased concentration of triclosan (Fig. 1) supporting the hypothesis that high triclosan concentrations induce efflux and thereby explain why cross resistance to antibiotics is primarily observed when the bacteria are also subjected to high concentrations of triclosan. This is likely since resistance towards SXT and fluoroquinolones can occur via efflux. The ArcAB-TolC efflux pumps are important for triclosan resistance [11] and these pumps have also been shown to directly contribute to flouroquinolone (e.g. ENR) resistance in Salmonella [40, 41]. The efflux systems EmrAB and ArcEF have been shown to be important for both triclosan resistance [10] and trimethoprim resistance [42]. Our results support the previous observations of triclosan dependent increase of antibiotic resistance in different bacteria [43-46].

Our data demonstrated that the mutations in T4/74C only had minor effects on adhesion and invasion to a cultured cell line. In contrast to this, the mutations in TDTU3C did have significant effect on adhesion and invasion, however, the inoculum was slightly lower for this strain compared to the wild type strain, and this might explain this difference. Previous work on triclosan exposed $S$. Typhimurium has showed reduced ability to invade Caco-2 epithelial cells [4]. This difference could be due to differences in cell lines and different mutations in the strains investigated.

\section{Conclusion}

The current study has demonstrated that high level resistance to triclosan can be achieved by mutations in both fabI and in a sigma factor. The combinations of these mutations do not compromise growth, but induces efflux, which in turn may be accountable for the observed antibiotic resistance. Further research is needed to clarify the role of sigma factor mutations in high level triclosan resistance.

\section{Abbreviations \\ CFU: Colony forming units.}

\section{Competing interests}

The authors declare that they have no competing interests.

\section{Authors' contributions}

MRG, JEO and LETH planned the experiments. MRG performed adaptationexperiments, SNP-analysis, efflux, Northern blot and cell assays. MRG and LETH performed phage-transduction and MIC-determination. MRG and LETH drafted the manuscript and all authors read and commented on this. All authors approved the final manuscript.

\section{Acknowledgements}

We gratefully acknowledge Karl Pedersen, Technical University of Denmark, National Food Institute, Department of Microbiology and Risk Assessment for providing the S. Typhimurium DTU3 (DFVF/FOOD 2009-60-277) and Lotte Jelsbak, Roskilde University, for providing the S. Typhimurium 4/74 rpos-mutant used in the study.
This work was supported by a PhD grant from University of Copenhagen and a grant from The Danish Council for Strategic Research (grant number 2101-08-0030)

Received: 12 January 2015 Accepted: 12 May 2015

Published online: 19 May 2015

\section{References}

1. EFSA, ECDC. The European Union summary report on trends and sources of zoonoses, zoonotic agents and food-borne outbreaks in 2012. EFSA J. 2014;12(2):3547.

2. EFSA, ECDC. The European Union summary report on antimicrobial resistance in zoonotic and indicator bacteria from humans, animals and food in 2010. EFSA J. 2012;10(3):2598.

3. Russell AD. Biocide use and antibiotic resistance: the relevance of laboratory findings to clinical and environmental situations. Lancet Infect Dis. 2003;3(12):794-803.

4. Karatzas KAG, Webber MA, Jorgensen F, Woodward MJ, Piddock LV, Humphrey TJ. Prolonged treatment of Salmonella enterica serovar Typhimurium with commercial disinfectants selects for multiple antibiotic resistance, increased efflux and reduced invasiveness. J Antimicrob Chemother. 2007;60(5):947-55.

5. Whitehead RN, Overton TW, Kemp CL, Webber MA. Exposure of Salmonella enterica serovar Typhimurium to high level biocide challenge can select multidrug resistant mutants in a single step. PLoS One. 2011;6(7):e22833.

6. Chapman JS. Biocide resistance mechanisms. Int Biodeterior Biodegrad. 2003;51(2):133-8

7. McMurry LM, Oethinger M, Levy SB. Triclosan targets lipid synthesis. Nature. 1998;394(6693):531-2.

8. Maillard JY. Bacterial target sites for biocide action. J Appl Microbiol. 2002;92(Suppl):16S-27.

9. Levy SB. Active efflux, a common mechanism for biocide and antibiotic resistance. J Appl Microbiol. 2002;92:65S-71.

10. Rensch U, Nishino K, Klein G, Kehrenberg C. Salmonella enterica serovar Typhimurium multidrug efflux pumps EmrAB and AcrEF support the major efflux system ArCAB in decreased susceptibility to triclosan. Int J Antimicrob Agents. 2014;44(2):179-80.

11. Webber MA, Randall LP, Cooles S, Woodward MJ, Piddock LJ. Triclosan resistance in Salmonella enterica serovar Typhimurium. J Antimicrob Chemother. 2008;62(1):83-91.

12. Webber MA, Coldham NG, Woodward MJ, Piddock LJV. Proteomic analysis of triclosan resistance in Salmonella enterica serovar Typhimurium. J Antimicrob Chemother. 2008;62(1):92-7.

13. Birošová L, Mikulášová M. Development of triclosan and antibiotic resistance in Salmonella enterica serovar Typhimurium. J Med Microbiol. 2009;58(Pt 4):436-41.

14. McMurry LM, Oethinger M, Levy SB. Overexpression of marA, soxS, or acrAB produces resistance to triclosan in laboratory and clinical strains of Escherichia coli. FEMS Microbiol Lett. 1998;166(2):305-9.

15. Sivaraman S, Zwahlen J, Bell AF, Hedstrom L, Tonge PJ. Structure - activity studies of the inhibition of Fabl, the Enoyl Reductase from Escherichia coli, by Triclosan: kinetic analysis of mutant Fabls. Biochemistry. 2003;42(15):4406-13.

16. Bailey AM, Constantinidou C, Ivens A, Garvey MI, Webber MA, Coldham N, et al. Exposure of Escherichia coli and Salmonella enterica serovar Typhimurium to triclosan induces a species-specific response, including drug detoxification. J Antimicrob Chemother. 2009;64(5):973-85.

17. Maloy SR, Stewart VJ, Taylor RK. Genetic Analysis of Pathogenic Bacteria: A Laboratory Manual. Cold Spring Harbor, NY: Spring Harbor Laboratory Press; 1996

18. Datsenko KA, Wanner BL. One-step inactivation of chromosomal genes in Escherichia coli K-12 using PCR products. Proc Natl Acad Sci U S A. 2000;97(12):6640-5.

19. Jelsbak $L$, Thomsen LE, Wallrodt I, Jensen PR, Olsen JE. Polyamines are required for virulence in Salmonella enterica serovar Typhimurium. PLoS One. 2012;7(4):e36149.

20. Nielsen LN, Larsen MH, Skovgaard S, Kastbjerg V, Westh $H$, Gram L, et al. Staphylococcus aureus but not Listeria monocytogenes adapt to triclosan and adaptation correlates with increased fabl expression and agr deficiency. BMC Microbiol. 2013;13(1):177.

21. Walsh SE, Maillard JY, Russell AD, Catrenich CE, Charbonneau DL, Bartolo RG. Development of bacterial resistance to several biocides and effects on antibiotic susceptibility. J Hosp Infect. 2003;55(2):98-107. 
22. Gantzhorn MR, Pedersen K, Olsen JE, Thomsen LE. Biocide and antibiotic susceptibility of Salmonella isolates obtained before and after cleaning at six Danish pig slaughterhouses. Int J Food Microbiol. 2014;181:53-9.

23. Richardson EJ, Limaye B, Inamdar H, Datta A, Manjari KS, Pullinger GD, et al. Genome sequences of Salmonella enterica serovar Typhimurium, Choleraesuis, Dublin, and Gallinarum strains of well- defined virulence in food-producing animals. J Bacteriol. 2011;193(12):3162-3.

24. Martins M, Couto I, Viveiros M, Amaral L. Identification of efflux-mediated multi-drug resistance in bacterial clinical isolates by two simple methods. Methods Mol Biol. 2010;642:143-57.

25. Thomsen L, Gottlieb C, Gottschalk S, Wodskou T, Kristensen H-H, Gram L, et al, The heme sensing response regulator HssR in Staphylococcus aureus but not the homologous RR23 in Listeria monocytogenes modulates susceptibility to the antimicrobial peptide plectasin. BMC Microbiol. 2010;10(1):307.

26. Wallrodt I, Jelsbak L, Thorndahl L, Thomsen LE, Lemire S, Olsen JE. The putative thiosulfate sulfurtransferases PspE and GlpE contribute to virulence of Salmonella Typhimurium in the mouse model of systemic disease. PLOS One. 2013;8(8):e70829.

27. R Development Core Team. A language and environment for statistica computing. version 2140th ed. Vienna, Austria: R Foundation for Statistical Computing; 2011.

28. Bates D, Maechler M, Bolker B, Walker S. Ime4: Linear mixed-effects models using Eigen and S4. 10-4th ed. 2013.

29. Hothorn T, Bretz F, Westfall P. Simultaneous inference in general parametric models. Biom J. 2008;50(3):346-63.

30. Jones PW, Collins P, Aitken MM. Passive protection of calves against experimental infection with Salmonella typhimurium. Vet Rec. 1988;123(21):536-41.

31. Rensch U, Klein G, Kehrenberg C. Analysis of triclosan-selected Salmonella enterica mutants of eight serovars revealed increased aminoglycoside susceptibility and reduced growth rates. Plos One. 2013;8(10):e78310.

32. Russell AD. Bacterial resistance to disinfectants: present knowledge and future problems. J Hosp Infect. 1999;43(Suppl):S57-68.

33. Condell O, Sheridan Á, Power KA, Bonilla-Santiago R, Sergeant K, Renaut J, et al. Comparative proteomic analysis of Salmonella tolerance to the biocide active agent triclosan. J Proteomics. 2012;75(14):4505-19.

34. Gomez Escalada M, Harwood JL, Maillard J-Y, Ochs D. Triclosan inhibition of fatty acid synthesis and its effect on growth of Escherichia coli and Pseudomonas aeruginosa. J Antimicrob Chemother. 2005;55(6):879-82.

35. Heath RJ, Rock CO. Microbiology: A triclosan-resistant bacterial enzyme. Nature. 2000;406(6792):145-6.

36. Heath RJ, Rubin JR, Holland DR, Zhang E, Snow ME, Rock CO. Mechanism of triclosan inhibition of bacterial fatty acid synthesis. J Biol Chem. 1999:274(16):11110-4.

37. Archer CD, Elliott T. Transcriptional control of the nuo operon which encodes the energy-conserving NADH dehydrogenase of Salmonella typhimurium. J Bacteriol. 1995;177(9):2335-42.

38. Chuanchuen R, Pathanasophon P, Khemtong S, Wannaprasat W, Padungtod P. Susceptibilities to antimicrobials and disinfectants in Salmonella isolates obtained from poultry and swine in Thailand. J Vet Sci. 2008;70(6):595-601.

39. Randall LP, Cooles SW, Coldham NG, Penuela EG, Mott AC, Woodward MJ, et al. Commonly used farm disinfectants can select for mutant Salmonella enterica serovar Typhimurium with decreased susceptibility to biocides and antibiotics without compromising virulence. J Antimicrob Chemother. 2007:60(6):1273-80.

40. Baucheron S, Imberechts H, Chaslus-Dancia E, Cloeckaert A. The ArcB multidrug transporter plays a major role in high-level fluoroquinolone resistance in Salmonella enterica serovar Typhimurium phage type DT204. Microb Drug Resist. 2002;8(4):281-9.

41. Akiba M, Nakaoka Y, Kida M, Ishioka Y, Sameshima T, Yoshii N, et al. Changes in antimicrobial susceptibility in a population of Salmonella enterica serovar Dublin isolated from cattle in Japan from 1976 to 2005. J Antimicrob Chemother. 2007;60(6):1235-42.

42. Barrero MA, Pietralonga PA, Schwarz DG, Silva Jr A, Paula SO, Moreira MA. Effect of the inhibitors phenylalanine arginyl B-naphthylamide (PABN) and 1-(1-naphthylmethyl)-piperazine (NMP) on expression of genes in multidrug efflux systems of Escherichia coli isolates from bovine mastitis. Res Vet Sci. 2014:97(2):176-81.

43. Huovinen P. Resistance to trimethoprim-sulfamethoxazole. Clin Infect Dis. 2001;32(11):1608-14
44. Thorrold CA, Letsoalo ME, Dusé AG, Marais E. Efflux pump activity in fluoroquinolone and tetracycline resistant Salmonella and E. coli implicated in reduced susceptibility to household antimicrobial cleaning agents. Int J Food Microbiol. 2007;113(3):315-20.

45. Nikaido H, Pagès J-M. Broad specificity efflux pumps and their role in multidrug resistance of gram negative bacteria. FEMS Microbiol Rev. 2012;36(2):340-63.

46. Hernandez A, Ruiz FM, Romero A, Martinez JL. The binding of triclosan to SmeT, the repressor of the multidrug efflux pump SmeDEF, induces antibiotic resistance in Stenotrophomonas maltophilia. PLoS Pathog. 2011;7(6):e1002103.

\section{Submit your next manuscript to BioMed Central and take full advantage of:}

- Convenient online submission

- Thorough peer review

- No space constraints or color figure charges

- Immediate publication on acceptance

- Inclusion in PubMed, CAS, Scopus and Google Scholar

- Research which is freely available for redistribution 